\title{
DIRECT METHOD FOR PRODUCING SCANDIUM METAL AND SCANDIUM-ALUMINIUM INTERMETALLIC COMPOUNDS FROM THE OXIDES
}

\author{
Ana Maria Martinez, Karen Sende Osen, Henrik Gudbrandsen, Camilla Sommerseth, \\ Zhaohui Wang and Ove Darell \\ SINTEF Materials and Chemistry, 7465 Trondheim, Norway \\ Corresponding author: anamaria.martinez@sintef.no,+4798230425
}

Keywords: scandium metal, scandium-aluminium, FFC-process, electrochemical de-oxidation, scandium oxide, molten chlorides

\begin{abstract}
The electrochemical de-oxidation process, also called FFC-Cambridge process, has been proposed previously to produce reactive metals and their alloys through reduction of their metal oxides. The process works by introducing metal oxides into a molten salt bath where it is electrolysed to form metal powders offering both economic and environmental benefits over the traditional metal production methods.

Within the frame of the EU-financed project SCALE (GA 730105), SINTEF is investigating the optimal parameters of the direct electrolytic reduction of $\mathrm{Sc}_{2} \mathrm{O}_{3}$ and $\mathrm{Sc}_{2} \mathrm{O}_{3}-\mathrm{Al}_{2} \mathrm{O}_{3}$ precursors (dross from Al-Sc alloy production), giving Sc and Al-Sc metallic powders, respectively, in a molten $\mathrm{CaCl}_{2}$-based electrolyte at a working temperature of ca. $900{ }^{\circ} \mathrm{C}$. The influence of the applied cathodic potential in the reduction mechanism and in the metal product has been studied.
\end{abstract}

\section{Introduction}

Scandium is currently produced by calciothermic reduction of $\mathrm{ScF}_{3}$, which is obtained by fluorination of the oxide. On the other hand, Al-Sc alloys are produced by mixing Sc with overheated liquid Al and following melt crystallization [1]. There are several drawbacks in these methods, i.e. high production costs, high price of pure Sc and high losses during alloy preparation, and difficulties in controlling the cooling process parameters to obtain a uniform alloy crystallization.

Innovative reduction technologies using oxidic raw materials in both Sc and Sc-Al master alloy production are sought. In this way, savings in process steps with respect to the current process, and the subsequent economical savings could be achieved.

A viable route for reducing the cost to produce active metals and their alloys by reducing metal oxides was proposed by Chen et al, called the FFC-Cambridge process [2]. There are many papers devoted to the FFC process applied to several metals and alloys, the most important being titanium. The process comprises a simple one-step electrochemical method that reduces the metal oxide to metal powder, and it has been scaled-up for titanium and tantalum [3]. Then, the direct reduction route of the scandium oxide and also the reduction of an aluminiumscandium oxide mix to Al-Sc using this method could be a viable and low cost route to produce the pure Sc metal and Al-Sc alloy.

The process consists of using a solid oxide cathode consisting of pure $\mathrm{Sc}_{2} \mathrm{O}_{3}$ or $\mathrm{Al}_{2} \mathrm{O}_{3}-\mathrm{Sc}_{2} \mathrm{O}_{3}$ mixture for the Sc metal and Al-Sc alloy, respectively, and introduced in a molten $\mathrm{CaCl}_{2}$-based electrolyte with a relatively high oxide solubility at the working temperature of ca. $900^{\circ} \mathrm{C}$ [4]. The composition of the oxide-mix in the cathode precursor might allow the reduction of $\mathrm{Sc}$ rich alloys $\left(\mathrm{AlSc}_{3}\right.$ or $\mathrm{AlSc}_{2}$ ). The oxide ions released during the cathode reaction will diffuse in the molten salt electrolyte, being then discharged at the anode. The schematics of the process is depicted in Figure 1.

The reactions taking place at the cathode and anode, as well as the overall electrochemical reactions when using graphitic or inert anodes, are gathered in Table 1 . The anode reaction product is $\mathrm{CO}_{2}$ or oxygen gas when using graphite or inert anodes, respectively. Up to date, and despite the efforts of the scientific community through the last decades, no material to be used as inert anode has been demonstrated to have a good performance and decent cathode product quality. Therefore, the use of graphite anode is the only remaining option. This is demanding a good control over the electrolysis operation, and especially over the anode reaction, so the release of unwanted chloride-containing anode reaction products, i.e. $\mathrm{Cl}_{2}$ or $\mathrm{COCl}_{2}$, is avoided. 


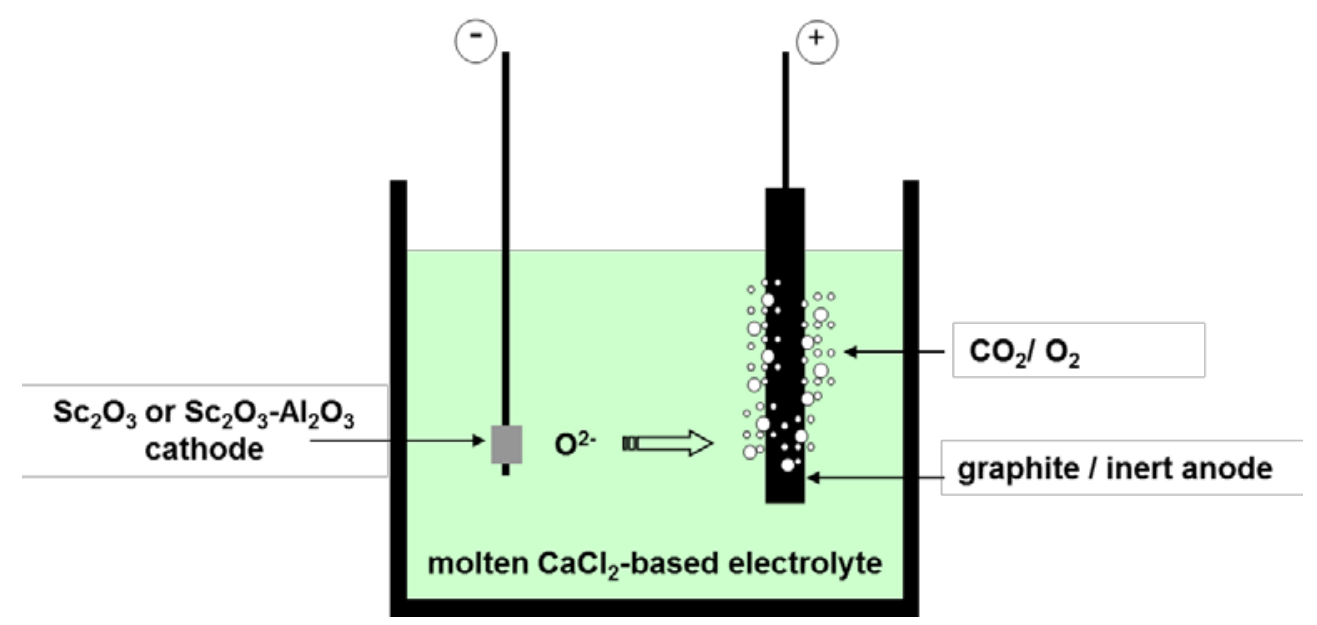

Figure 1. Schematics of the FFC process applied to Sc and SC-Al reduction directly from their oxides.

Table 1. Electrochemical reactions in the FFC process for Sc and Al-Sc reduction from oxide precursors.

\begin{tabular}{|c|c|c|c|}
\hline & Cathode reaction & Anode reaction & Total cell reaction \\
\hline \multirow{2}{*}{ Sc metal } & \multirow{2}{*}{$\mathrm{Sc}_{2} \mathrm{O}_{3}(\mathrm{~s})+6 \mathrm{e}^{-} \rightarrow 2 \mathrm{Sc}(\mathrm{s})+3 \mathrm{O}^{2-}$} & \multirow{4}{*}{$\begin{array}{c}2 \mathrm{O}^{2-} \rightarrow \mathrm{O}_{2}+4 \mathrm{e}^{-} \\
\text {(inert anode) } \\
2 \mathrm{O}^{2-}+\mathrm{C} \rightarrow \mathrm{CO}_{2}(\mathrm{~g})+4 \mathrm{e}^{-} \\
\text {(graphite anode) }\end{array}$} & $\begin{array}{l}2 \mathrm{Sc}_{2} \mathrm{O}_{3}(\mathrm{~s}) \rightarrow 4 \mathrm{Sc}(\mathrm{s})+3 \mathrm{O}_{2}(\mathrm{~g}) \\
\text { (inert anode) }\end{array}$ \\
\hline & & & $\begin{array}{l}2 \mathrm{Sc}_{2} \mathrm{O}_{3}(\mathrm{~s})+3 \mathrm{C}(\mathrm{s}) \rightarrow 4 \mathrm{Sc}(\mathrm{s})+3 \mathrm{CO}_{2}(\mathrm{~g}) \\
\quad \text { (graphite anode) }\end{array}$ \\
\hline \multirow[t]{2}{*}{ Sc-Al alloy } & \multirow{2}{*}{$\begin{array}{l}\mathrm{Al}_{2} \mathrm{O}_{3}(\mathrm{~s})+3 \mathrm{Sc}_{2} \mathrm{O}_{3}(\mathrm{~s})+24 \mathrm{e}^{-} \\
\rightarrow 2 \mathrm{AlSc}_{3}(\mathrm{~s})+12 \mathrm{O}^{2-}\end{array}$} & & $\begin{array}{l}\mathrm{Al}_{2} \mathrm{O}_{3}(\mathrm{~s})+3 \mathrm{Sc}_{2} \mathrm{O}_{3}(\mathrm{~s}) \rightarrow 2 \mathrm{AlSc}_{3}(\mathrm{~s})+6 \mathrm{O}_{2}(\mathrm{~g}) \\
\text { (inert anode) }\end{array}$ \\
\hline & & & $\begin{array}{l}\mathrm{Al}_{2} \mathrm{O}_{3}(\mathrm{~s})+3 \mathrm{Sc}_{2} \mathrm{O}_{3}(\mathrm{~s})+6 \mathrm{C} \rightarrow 2 \mathrm{AlSc}_{3}(\mathrm{~s})+6 \mathrm{CO}_{2}(\mathrm{~g}) \\
\text { (graphite anode) }\end{array}$ \\
\hline
\end{tabular}

Within the frame of the EU-financed project SCALE (GA 730105), SINTEF is investigating the possibility of using the direct electrolytic reduction of $\mathrm{Sc}_{2} \mathrm{O}_{3}$ and $\mathrm{Sc}_{2} \mathrm{O}_{3}-\mathrm{Al}_{2} \mathrm{O}_{3}$ precursors, leading to Sc and Al-Sc metallic powders, respectively. The Sc-containing material used as precursors is extracted from European metallurgical byproducts, i.e. bauxite residues resulting from alumina production and acid wastes from $\mathrm{TiO}_{2}$ pigment production. The direct use of discarded dross from Al-Sc alloy production will also be assessed.

In this paper, initial results obtained during electrochemical de-oxidation experiments using synthetic $\mathrm{Sc}_{2} \mathrm{O}_{3}$ as raw material, also in the presence of $\mathrm{Al}_{2} \mathrm{O}_{3}$ are reported. The aim was to investigate the reduction mechanisms and optimize the electrolysis parameters, i.e. cell voltage and time, giving a complete reduction of the oxide precursors to metal without risking the release of harmful anode products, i.e. chloride-containing compounds.

\section{Experimental}

The experimental cell consisted of a programmable vertical tight furnace with a mullite liner that housed an alumina crucible (Øint $=45 \mathrm{~mm}$, Friatec) used as electrolyte container. A water-cooled lid supported a metal top plate that allowed the insertion of anodes, cathodes, reference electrode and thermocouple.

The electrolyte was $\mathrm{CaCl}_{2}$ with a small addition of $\mathrm{NaCl}$, typically $5 \mathrm{wt} \%$. This was due to the use of a ceramic $\mathrm{Na}^{+}$selective membrane as reference electrode container. Moreover, some oxide ions were added (ca. $1 \mathrm{~mol} \%$ ) in the form of $\mathrm{CaO}$ from the beginning of the electrolysis, thus avoiding chlorine evolution at the first stages of the electroreduction process. All the chemicals were dried at $200{ }^{\circ} \mathrm{C}$ for at least $48 \mathrm{~h}$ prior to use. The working temperature was kept at $900^{\circ} \mathrm{C}$, and monitored continuously using a thermocouple type S (Pt-Pt $10 \% \mathrm{Rh}$ ) shielded by a closed-end alumina tube.

The cathode precursors were pellets of $\mathrm{Sc}_{2} \mathrm{O}_{3}$ made by pressing (uniaxial press, 1 tonne) certain amounts of the oxide powder which were subsequently sintered in air at $1200^{\circ} \mathrm{C}\left(200{ }^{\circ} \mathrm{C} / \mathrm{h}\right.$ heating rate $)$ for $2 \mathrm{~h}$. The pellets obtained (1 cm diameter and ca. $1 \mathrm{~cm}$ height) were mechanically stable and could be machined and drilled to be 
connected to a Ta wire used as current collector. The anodes were made of graphite with Mo wire as current collector. The reference electrode was based on the $\mathrm{Ag} / \mathrm{AgCl}$ system and housed in a closed-end mullite tube. It consisted of a silver wire (1mm diameter) dipped into a silver chloride solution $\left(0.75 \mathrm{~mol} \mathrm{~kg}^{-1}\right) \mathrm{in}$ the $\mathrm{CaCl}_{2}$-based electrolyte.

The electrolysis experiments were run potentiostatically by applying a constant potential to the cathode precursor measured against the AgCl/Ag reference electrode, using a PARSTART 4000, and the cell voltage and temperature were recorded by means of a multichannel Keithley 2000 Multimeter.

Phase composition of the various reduction products was determined through X-ray diffraction analysis using a Bruker D8 Focus diffractometer with a LynxEye PSD detector (Bruker AXS, Karlsruhe, Germany), and the microstructure and chemical composition was investigated by means of scanning electron microscopy using LVSEM HITACHI S-3400N equipped with an energy dispersive spectrometer (Hitachi, Japan).

\section{Results and Discussion}

The exact reaction path occurring during the electrochemical de-oxidation of metal oxides in a $\mathrm{CaCl}_{2}$-based electrolyte is not fully understood. Whereas the FFC-Cambridge process inventors claim that it is a pure electrochemical mechanism, Ono and Suzuki [5] state that it is a combined electrochemical and calciothermic reduction with the calcium metal generated "in-situ" by electrochemical reaction (see Table 2).

Table 2. Reduction mechanism in the electrochemical de-oxidation of a metallic oxide (MO) according to: 1) FFCCambridge process inventors; and 2) Ono and Suzuki.

\begin{tabular}{cc}
\hline \multicolumn{2}{c}{ Electrochemical de-oxidation of MO reduction mechanism } \\
\hline According to 1) FFC-Cambridge inventors & According to 2) Ono and Suzuki \\
\hline $2 \mathrm{MO}(\mathrm{s})+\mathrm{Ca}^{2+}+2 \mathrm{e}^{-} \rightarrow 2 \mathrm{M}(\mathrm{s})+\mathrm{CaO}$ (diss) & $\mathrm{Ca}^{2+}+2 \mathrm{e}^{-} \rightarrow \underset{\mathrm{Ca} \text { (diss) }}{\downarrow}$ \\
$\mathrm{MO}(\mathrm{s})+\mathrm{Ca}$ (diss) $\rightarrow \mathrm{M}$ (s) $+\mathrm{CaO}$ (diss)
\end{tabular}

The standard reduction potentials of relevant reactions in the electrochemical de-oxidation process, were calculated using the HSC [6] database and are gathered in Table 3.

Table 3. Standard reduction potentials of different relevant reduction reactions, versus AgCl/Ag reference system. Temperature $900{ }^{\circ} \mathrm{C}$.

\begin{tabular}{ll}
\hline Reduction reactions & $\mathbf{E}^{\mathbf{0}} \mathbf{v s} \mathbf{A g} / \mathbf{A g C l} / \mathbf{V}$ at $900{ }^{\circ} \mathbf{C}$ \\
\hline $\mathrm{Cl}_{2}+2 \mathrm{e}^{-} \rightarrow 2 \mathrm{Cl}^{-}$ & 0.8 \\
\hline $\mathrm{AgCl}+\mathrm{e}^{-} \rightarrow \mathrm{Ag}+\mathrm{Cl}^{-}$ & 0 \\
\hline $0.5 \mathrm{CO}_{2}+\mathrm{CaCl}_{2}+2 \mathrm{e}^{-} \rightarrow 0.5 \mathrm{C}+\mathrm{CaO}+2 \mathrm{Cl}^{-}$ & -0.8 \\
\hline $1 / 3 \mathrm{Al}_{2} \mathrm{O}_{3}+\mathrm{CaCl}_{2}+2 \mathrm{e}^{-} \rightarrow 2 / 3 \mathrm{Al}+\mathrm{CaO}+2 \mathrm{Cl}^{-}$ & -2.03 \\
\hline $\mathrm{CaCl}_{2}+2 \mathrm{e}^{-} \rightarrow \mathrm{Ca}+2 \mathrm{Cl}^{-}$ & -2.43 \\
\hline $1 / 3 \mathrm{Sc}_{2} \mathrm{O}_{3}+\mathrm{CaCl}_{2}+2 \mathrm{e}^{-} \rightarrow 2 / 3 \mathrm{Sc}+\mathrm{CaO}+2 \mathrm{Cl}^{-}$ & -2.48 \\
\hline
\end{tabular}

The values showed that scandium oxide most likely cannot be reduced by calcium metal at $900{ }^{\circ} \mathrm{C}$, which is in agreement with the work previously reported by Harata et al. [7].

Trying to investigate the optimal reduction parameters and the reduction mechanism, a set of experiments was carried out at different reduction potentials applied to the cathode precursor.

The scandium oxide precursors were reduced at -2.3 and $-2.4 \mathrm{~V}$ versus the AgCl/Ag reference electrode system for about $6 \mathrm{~h}$. In both cases, the cell voltages obtained were below $3 \mathrm{~V}$, then the anode voltage was able to be kept well below the values were chlorine evolution is expected (see Table 3). It was observed that the anode potential raised gradually with the electrolysis time, especially when the most cathodic voltage was applied. The current obtained in both cases ranged between 1 and $2 \mathrm{~A}$, and the anodic current densities varied from 0.12 and $0.05 \mathrm{~A}$ $\mathrm{cm}^{-2}$. Figure 2 shows the electrolysis data recorded during both experiments. 

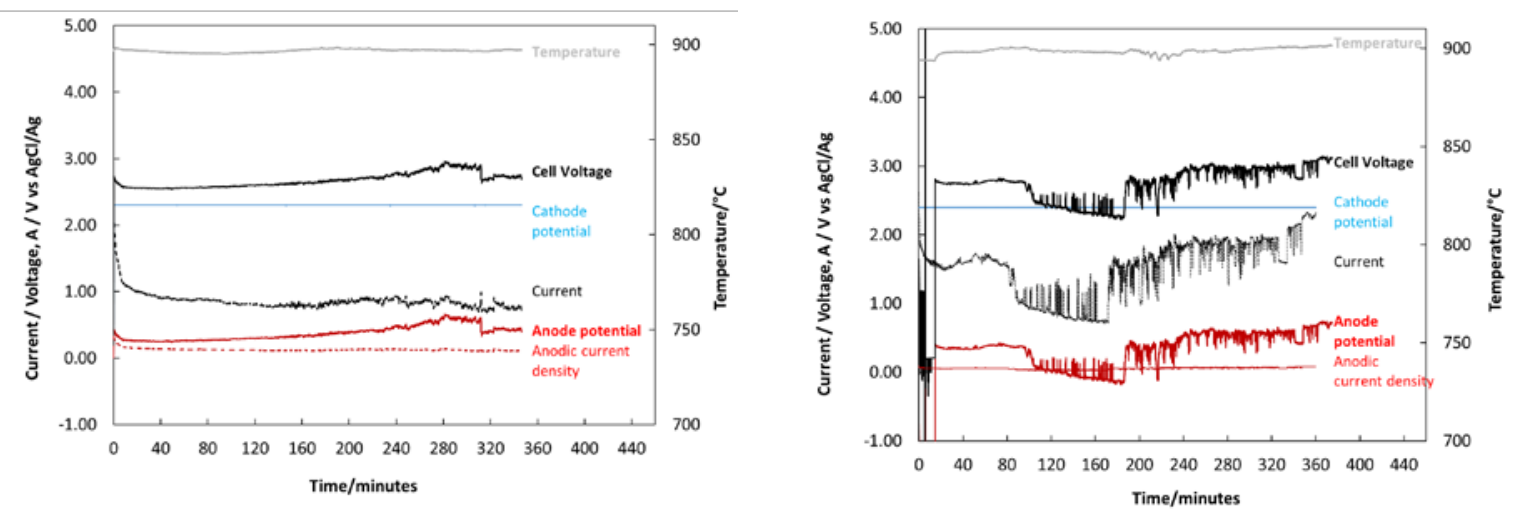

(A)

(B)

Figure 2. Electrolysis parameters recorded during the reduction of $\mathrm{SC}_{2} \mathrm{O}_{3}$ precursors when applying: $\left.A\right)-2.3 \mathrm{~V}$ and $\mathrm{B})-2.4 \mathrm{~V}$ versus $\mathrm{AgCl} / \mathrm{Ag}$ reference electrode system.

When the electrolysis was concluded, the cathode and the anode were lifted above the melt, and the cell was cooled down to room temperature under inert gas atmosphere. Examples of the $\mathrm{Sc}_{2} \mathrm{O}_{3}$ pellets before (A) and after (B) the electrolysis, are shown in Figure 3.

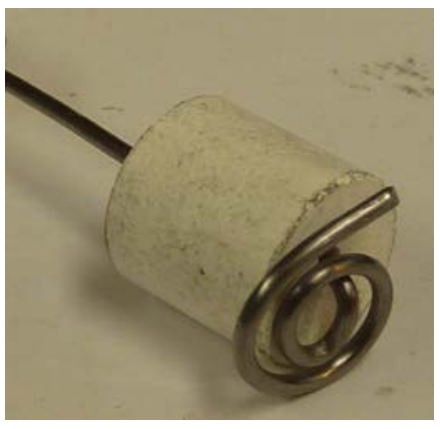

(A)

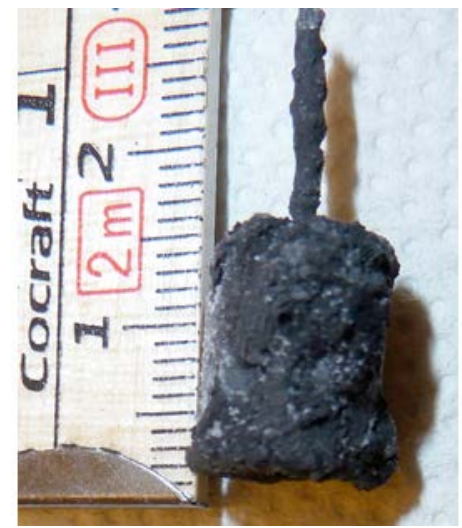

(B)

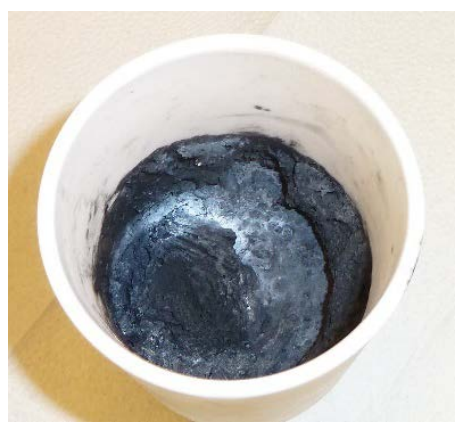

(C)

Figure 3. Examples of the $\mathrm{S}_{2} \mathrm{O}_{3}$ pellet (cathode) (A) before and after (B) electrolysis. $C$ ) alumina crucible and frozen electrolyte with carbon layer on top after electrolysis.

After each electrolysis experiment, the $\mathrm{Sc}_{2} \mathrm{O}_{3}$ precursors were surrounded by a black layer, which, after XRD and SEM-EDS analysis was found to be electrolyte $\left(\mathrm{CaCl}_{2}\right)$ and high amounts of carbon. The electrolyte also showed a black deposit on top (see Figure 3C). After dissolving the frozen electrolyte in water over night and subsequent filtration, a black deposit was recovered, which was determined to consist of carbon particles and crystals of calcium carbonate, found by XRD and FE-SEM/EDS analysis. The amount of carbon obtained increased when increasing the applied cathode potential.

This is in agreement with previous observations [8], showing that the use of carbon anodes is one of the main causes of the low current efficiency values and it represents a source of contamination of the cathode products in the electrochemical de-oxidation or FFC-Cambridge process.

The mechanism of carbon formation is the following. Both the solubility of $\mathrm{CO}_{2}$ gas [9] and oxide ions, or $\mathrm{CaO}$, is high in $\mathrm{CaCl}_{2}$-based electrolytes at the working temperature. Then, dissolved carbonate species are formed in the electrolyte, according to the reaction shown in Eq 1.

Eq 1

$$
\mathrm{CO}_{2}(\mathrm{~g})+\mathrm{CaO} \text { (diss) } \rightarrow \mathrm{CaCO}_{3} \text { (diss) }
$$

Since the solubility of calcium carbonate increases with increasing $\mathrm{CaO}$ activity and reduced temperature [9], carbonate ions can diffuse towards the cathode as the de-oxidation process proceeds, then being reduced to carbon [10], according to Eq 2, or even carbide. 
The low-density carbon formed floats to the top of the electrolyte causing short-circuiting in the electrolyte cell. Thus, the use of inert anodes is highly desired to circumvent this problem.

However, the provision of a suitable inert anode material still seems to be rather challenging. In an eventual industrial process, this deficiency could be circumvented by controlling the formation of the $\mathrm{CO}_{2}$ gas bubbles into being homogeneously small so that they can easily escape once released at the graphite anode. Optimization of the anode shape/geometry could also be an option, as in aluminium electrolysis cells [11].

After the electrolysis experiments, the cathodes were cut and polished with absolute ethanol without removing the remaining salt, prior to SEM/EDS observations. The results showed no evidence of Sc metal at any of the applied cathodic potentials, i.e. -2.3 and -2.4 vs $\mathrm{AgCl} / \mathrm{Ag}$ reference system. However, the presence of $\mathrm{CaSc}_{2} \mathrm{O}_{3}$ needles were evidenced, formed by reaction of the precursor with the dissolved $\mathrm{CaO}$, according to Eq 3:

$$
\mathrm{Sc}_{2} \mathrm{O}_{3}(\mathrm{~s})+\mathrm{CaO} \text { (diss) } \rightarrow \mathrm{CaSc}_{2} \mathrm{O}_{3}(\mathrm{~s})
$$

Since no $\mathrm{Sc}_{2} \mathrm{O}_{3}$ was reduced during the experiments, the cathode reaction was, presumably, the underpotential deposition (UPD) of Ca metal on the Ta current collector. UPD of Ca is the electrodeposition of calcium at activity lower than one, which is favoured by the high solubility of $\mathrm{Ca}$ metal in the $\mathrm{CaCl}_{2}$-based electrolyte [12], giving species like $\mathrm{Ca}_{2}{ }^{2+}$ or $\mathrm{Ca}^{+}[13,14]$. The formed Ca metal species dissolved can further react with the anode gas in the electrolyte giving carbon, according to the very exothermic reaction shown in Eq 4. This might also be another source of carbon formation during the electro-reduction process, occurring more extensively at higher cathodic potentials applied.

Eq 4

$$
\mathrm{Ca} \text { (diss) }+\mathrm{CO}_{2} \text { (diss) } \rightarrow \mathrm{CaO} \text { (diss) }+\mathrm{C}(\mathrm{s})
$$

Due to the fact that the cathode reaction was not the electrochemical de-oxidation of $\mathrm{Sc}_{2} \mathrm{O}_{3}$, it was not possible to keep the oxide ions balance, and depletion of the $\mathrm{CaO}$ added to the electrolyte at the beginning of the experimentation occurred. This explained the registered increase anode potential with time (see Figure 2).

Another experiment was carried out where a piece of $\mathrm{Al}_{2} \mathrm{O}_{3}$ was placed in contact with the $\mathrm{Sc}_{2} \mathrm{O}_{3}$ precursor applying a cathode voltage of $-2.4 \mathrm{~V}$ vs $\mathrm{AgCl} / \mathrm{Ag}$ for $3 \mathrm{~h}$. In this case, the cross-section of the cathode after electrolysis evidenced the presence of a metallic phase. SEM/EDS analysis showed Al and Sc metals (see Figure 4), together with some entrapped electrolyte. Further XRD analysis of the metal produced evidenced the presence of $\mathrm{Al}_{3} \mathrm{Sc}$ phases (see Figure 5).

The results showed that at the applied cathodic potential (-2.4 V vs AgCl/Ag), $\mathrm{Al}_{2} \mathrm{O}_{3}$ could be reduced to liquid aluminium (see Table 3), and that the reduction of $\mathrm{Sc}_{2} \mathrm{O}_{3}$ can then take place subsequently, as Sc metal can be deposited at activities lower than one, i.e. at more positive potentials, due to the formation of intermetallic $\mathrm{Al}_{3} \mathrm{Sc}$ compound. This is in agreement with the work published by Harata et al [7]. 


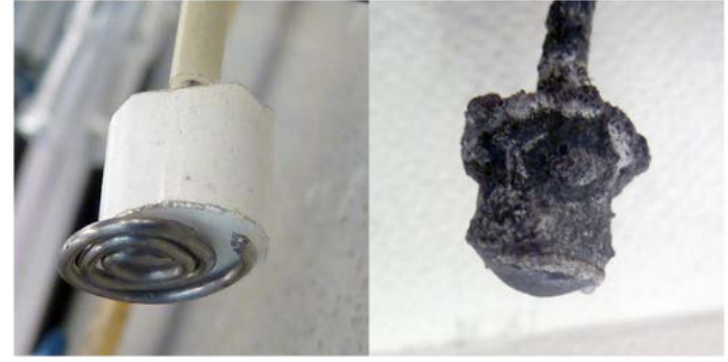

(A)
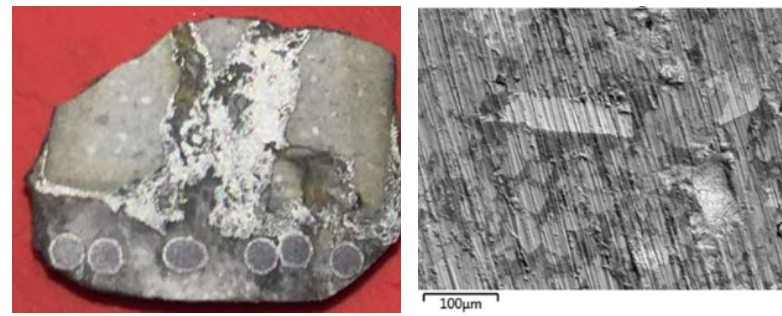

(B)

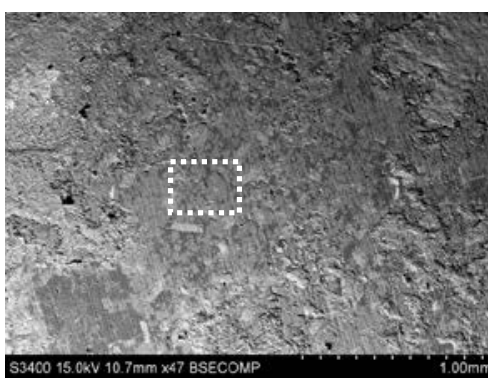

(C)
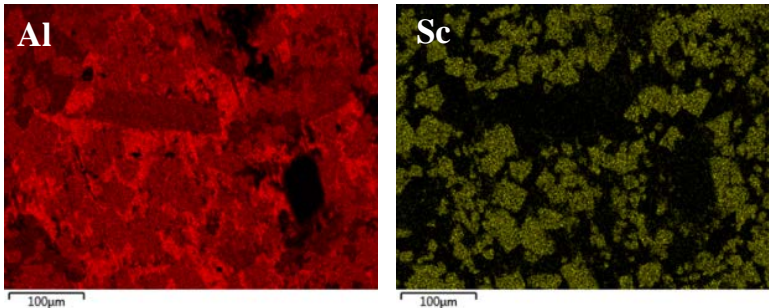

(D)

Figure 4. A) Picture showing the $\mathrm{Sc}_{2} \mathrm{O}_{3}$ precursor in contact with $\mathrm{Al}_{2} \mathrm{O}_{3}$ before and after the electrolysis; $B$ ) Cross section of the $\mathrm{SC}_{2} \mathrm{O}_{3}$ precursor after electrolysis, showing the formed metal phase; $\mathrm{C}$ ) Back scattered electron image of the metallic part, and D) EDS analysis of the zoomed image.

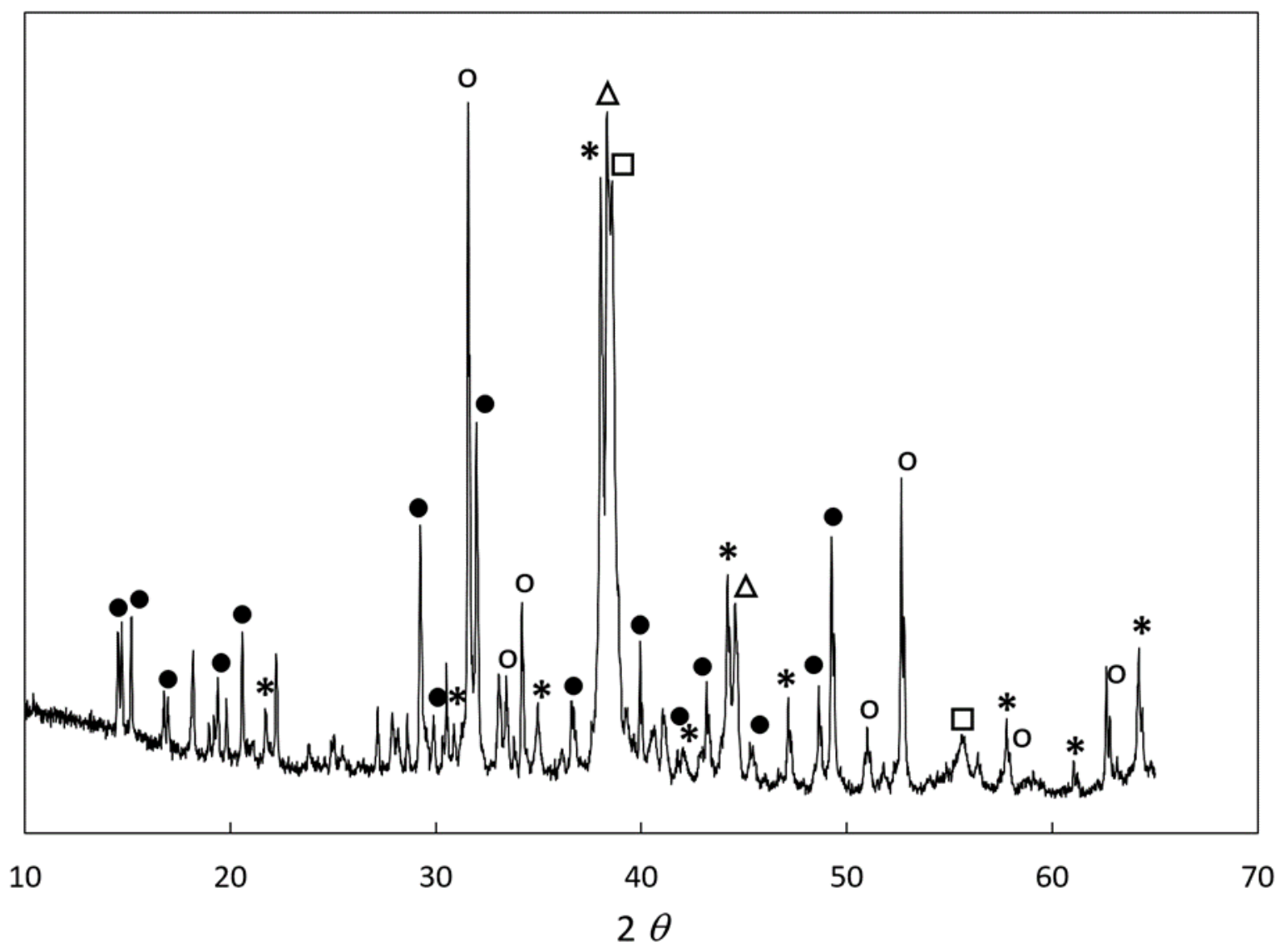

Figure 5. XRD diffractogram of the metal product showing the formation of ScAl/3 intermetallic compound. (*) Al3Sc; (O) Sc2O3; (O) $\mathrm{CaCl}_{2}(\mathrm{H} 2 \mathrm{O}) 2 ;(\triangle) \mathrm{Al} ;(\square) \mathrm{Ta}$. It is important to notice that the cathode product was not washed prior to the analysis, so remains of electrolyte are still present. 


\section{Summary and concluding remarks}

The results obtained during electrochemical de-oxidation experiments using synthetic $\mathrm{Sc}_{2} \mathrm{O}_{3}$ as raw material are reported. It was shown that Sc metal cannot be produced, unless $\mathrm{Al}$ metal is present. Thus, the reduction of $\mathrm{Sc}_{2} \mathrm{O}_{3}$ was achieved when $\mathrm{Al}_{2} \mathrm{O}_{3}$ was in contact with the $\mathrm{Sc}_{2} \mathrm{O}_{3}$ precursor, giving $\mathrm{Al}_{3} \mathrm{Sc}$ intermetallic compound as reaction product.

The work is on-going using dross from the Al-Sc alloy production. Other metals that form intermetallic compounds with Sc and that can easily be separated by vacuum distillation are also tested as current collectors, with $\mathrm{Zn}$ being the most attractive candidate.

\section{Acknowledgements}

This work has received funding from the European Union's H2020 Programme under Grant Agreement No. 730105 (SCALE project: http://scale-project.eu/).

\section{References}

1. J. Røyset and N. Ryum, Inter. Mater. Rev., 50 (2005) 19.

2. G.Z. Chen, D.J. Fray and T.W. Farthing, Nature, 407 (6802) (2000) 361.

3. http://www.metalysis.com/

4. D. A. Wenz, I. Johnson and R. D. Wolson: J. Chem. Eng. Data 14 (2) (1969) 250-252.

5. K. Ono and R. O. Suzuki, JOM, 54(2) (2002) 164-166.

6. HSC 7.11 (C) Outotec Research Center, 1974-2011.

7. M. Harata, T. Nakamura, H. Yakushiji and T.H. Okabe, Trans. Inst. Min. Metall. Sect. C, 117 (2) (2008).

8. E.g. S.J. Oosthuizen, J. South. African Inst. Min. and Metall., 11 (2011) 199-202.

9. M.Maeda and A.McLean, Trans. ISS (1986) 61-65.

10. Ito, Shimada and Kawamura, Proc. Electrochem. Soc. (1992) 574.

11. Aluminium, Vol 11 (2016) 38-39 (https://www.tomorrowtechnology.it/images/pdf/news/TT-Tomorrowarticle.pdf)

12. R.A.Sharma, J. Phys. Chem., 74 (1974) 3896-3900.

13. M.A. Bredie, in “Molten Salt Chemistry,” M. Blander (Ed.), Interscience, New York, (1964) p 364.

14. J.D. Corbett, in "Fused Salts” B.R. Sundheim (Ed.), McGraw-Hill, New York (1964) p 341. 